\title{
Utilization of Fiber Reinforcement Materials in Flexible Pavement Construction
}

\author{
T.Venkateswararao, R. Ratna Prasad, D.S.V.Prasad, D. Auditya Sai Ram
}

\begin{abstract}
By and by multi day's the masses and region traffic significance end up building up each day and surface rate additionally creating. On the off chance that there ought to emerge an event of bendy black-tops the mistake are occurs because of unprotected soil sub assessment and lack of customary substances. those bungle ups ascend in perspective on flinging, part, and division of roads, and so forth regularly broad soil burdens are over the top due to intermittent versions that element while in contact with water, it will swell and analysts even as water presses out. To impediment the regard we are utilizing sisal and jute fiber as stronghold material in the fly slag sub base courses laid with grasp to broad soil sub level. It wound up looked over the exploration office check consequences of changed compaction, direct shear and CBR that the most extraordinary appealing dimension of sisal and jute fiber is vague from $0.2 \%$ for fly soot material. Cyclic plate load assessments were performed inside the examination focus through setting a round metallic plate on model versatile blacktops. it's far checked that the most extraordinary weight passing on potential related to a ton less estimation of ricochet back evasion is gained for sisal and jute fiber strengthened stretch stood out from unreinforced fly red hot flotsam and jetsam stretch out inside the versatile black-top contraption laid on extensive sub grade.
\end{abstract}

Index Terms-Compaction, Shear, CBR, Flexible Pavement Model, sisal and jute fiber, fly ash

\section{INTRODUCTION}

Fly slag is a misfortune by way of using element from heat influence flowers, which makes use of coal as gas. As warm strength flora are spatially dispersed anyplace at some point of the world, utilization of fly crimson hot rubbish from those flowers for the road improvement not absolutely eats up mass measures of fly soot handling its change problems incompletely but butfulfill the improvement requirements. Huge scale use of fly powder in geotechnical improvement like banks, street sub-bases, helper land fill, as a substitution to the common earth fabric will contend with issues to be specific give up of stable waste trouble on one hand and game plan of a required development cloth on the alternative. Each the ones issues have come to be the opportunity to be important in the urban condition in mild of the way that maximum coal ended making flora are organized there and the supply of simple development cloth is in addition finishing up unusual. Particular kinds of materials are while dubious constantly utilized in severa auxiliary structuring sports along side turnpike running to energise development, better execution and abatement aid.

Revised Manuscript Received on April 12, 2019.

T.Venkateswararao, (Mail:venkateswararaothumati@gmail.com)

R.Ratna Prasad, (Mail: rekapalli.rp@gmail.com)

D.S.V.Prasad, (Mail: dsvp9@ yahoomail.com)

D.AudityaSai Ram,(Mail : dasairam102@gmail.com)
Over the span of the present day decade using geosynthetics has recorded a notable augmentation.

In order to employ fly ash in mass sums, handy belongings are being explored everywhere within the course of the sector to apply it for the development of barriers and boulevards (Hausmann, 1990 Veerendra Singh et al. 1996, Boominathan and Ratna Kumar 1996; Murthy, 1998), as flyash satisfies genuine shape necessities of concord and compressibility beside its loss of protection to deterioration and viable liquefaction beneath silly conditions (Guru Vittal and Murthy, 1998; Boominathan and Hari, 1999). Distinct materials for fiber used for have a look at are Glass fiber (Pazareet.Al, 2002), Nylon fiber (Jain et al, 2003), produced fiber like polypropylene fibers (Consoliet.Al, 1998), Polyester fiber (Kanirajet.Al, 2001) , remoted flexible obliterated tire (Lindh and Mattsson, 2004, and so forth. In any case, above fuses are generally exorbitant and nonbiodegradable achieving extra splendid costs with unrealistic ordinary consequences. This hassle can be enlightened through the use of domestically to be had ordinary fibers. Regular fibers like jute, sisal and jute, sabai grass fiber, and so on are generally to be had in immature nations like India effortlessly and their supply is ensured from agrarian merchandise. With an augmentation in flyash substance making plans tendencies of expansive soils may be progressed (Kumar and Sharma 2004). Tolerance Joseph et al., Praveen Kumar and pratap Singh (2007) has mulled over if there want to be an event of geosynthetic reinforced fly blazing trash all geosynthetic utilized in his exam are suitable for road sub bases laid on insufficiently assessed notable sand. Fortifying the earth with quick fiber seems to have first rate capability for application in lanes whilst alternate materials are furthermore used. Fiber reinforced flyash may be used as subbase in rural avenues. Sreedhar et al (2009) declared exploratory examination on the effect of turning into a member of geotextile strands in dry sand as unpredictable dispersed. They viewed unparalleled upgrade for CBR estimation of sand when mixed self-assertively with such fiber of all length of different point extents. The stack passing on breaking point of the flexible black-top structure is out and out extended for lime-bond offset flyashsubbase stretch out with admire to the flyashsubbase attain out on massive soil subgrade. Most first-rate lessening in throw regards are procured for the lime-concrete settled flyashsubbase stretch appeared in any other case on the subject of various stretches on extensive soil subgrade. Heaving of the large soil has stunningly lessened the pile 
passing on utmost of flexible black-pinnacle system.(Anjan Kumar, PrasadaRaju, Prasad 2009). There can be a noteworthy augmentation in the CBR regard for each excellent sand and silver sand at the same time as blending with erratically dispersed discrete favoredfiber (Maityet all the... 2011). Coordinated CBR and wellknown agent assessments inside the examination place for locating an appropriate fees of waste plastics, and quarry dust in soil pattern(2013). In angle at the results due to the fact the $\%$ of plastic waste grows the most top notch dry thickness decreases, thusly lessening the CBR regard and augmentation in \% of quarry buildup addition of most noteworthy dry thickness and CBR. Shear and CBR assessments inside the exploration focus, noticed from the results flyash substances bolstered with precise fees of waste plastics and sisal and jute, the proper costs were identical to zero.Three \% and $0.2 \%$ independently Sushma et al.,(2014). In angle at the exploration focus examinations did on this work Addition of (waste plastics + waste tire flexible) fuses in shake and flyash outcomes in an plain augmentation inside the shear houses and CBR cost.(Srinivasetall... .2015). Sand-fiber composite blended with $25 \%$ of moorum thru weight of sand may also healthy superb as subbase fabric for toll road having CBR extra big than 20 $\%$.(JoyantaMaity et all of the... .2017). Anyways, subsequent to no examination paintings has been represented on the Fly crimson hot flotsam and jetsam subbase braced with sisal and jute fiber for its software in flexible black-tops on sweeping soil subgrade.

Proper here an assignment is made to the suitability of sisal and jute fiber in fly blazing stays cloth. Beginning overdue, researchers numerous fields were attempted to cope with the problems restricted through mechanical wastes. Within the present exam compaction, direct shear and CBR,model black-top research exams had been driven within the exploration place for fly red hot flotsam and jetsam substances with special charges of sisal and jute fiber to gain ideal length of stronghold fabric.

\section{OBJECTIVE AND METHODOLOGY}

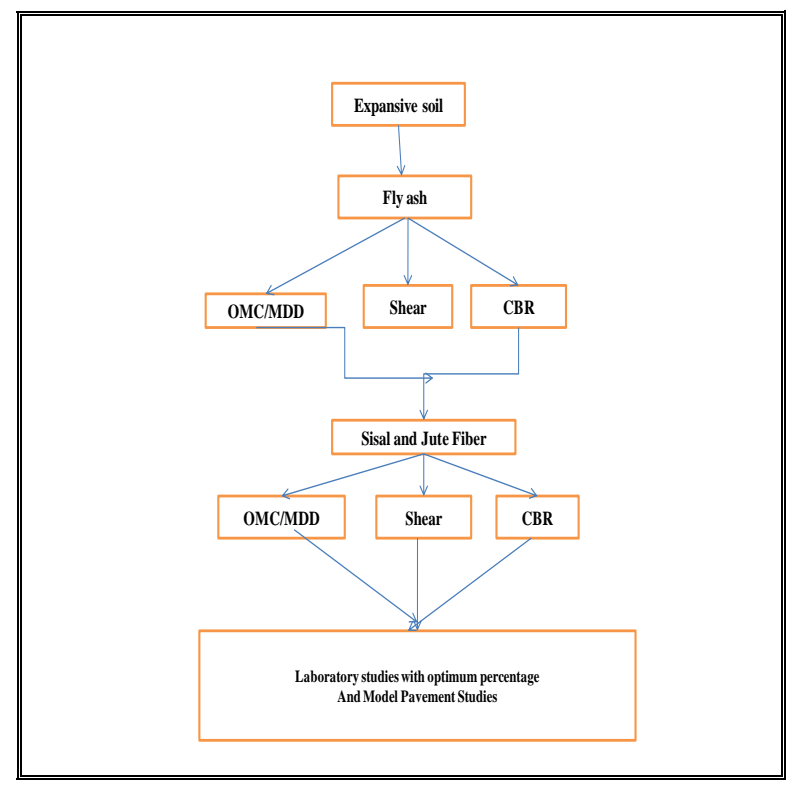

\section{MATERIALS}

The following materials are used in this study.

Expansive Soil:Expansive soil was collected from Amalapuram, East Godavari district; Expansive soil is used for this investigation as sub grade material.The soil properties are $\mathrm{OMC}=26.6 \%, \mathrm{MDD}=14.76 \mathrm{kN} / \mathrm{m}^{3}$, I.S. Classification $=\mathrm{CH}$, Soaked $\mathrm{CBR}=2.0 \%$, Liquid Limit $=79 \%$, Differential Free Swell $=190 \%$, Plasticity Index $=44 \%$, Specific Gravity $=2.65$, Cohesion $=80$, Angle of Friction $=5^{0}$.

Flyash:The fly ash was collected from Vijayawada thermal power station, fly ash is used as a sub base

Course in this work. The properties of fly ash are MDD = $14.40 \mathrm{kn} / \mathrm{m} \mathrm{3}, \mathrm{OMC}=19.5 \%$, soakedCBR $=7.1 \%$, Specific Gravity $=2.20$., Cohesion $=0.5 \mathrm{KN} / \mathrm{m} 2$, Angle of Friction $=$ $26.5^{0}$

Sisal and jute:Sisal and jute fibre was collected from locally available place inMangalagiri, Guntur District. Sisal and jute is used as fiber reinforcement material and its aspect ratio size of $0.1 \times 25 \mathrm{~mm}$.

Table 1Chemical Properties of Sisal and jute (Courtesy -NPTEL LECTURE TEXTILE FIBERS)

\begin{tabular}{|c|c|}
\hline Composition & $(\%)$ \\
\hline Cellulose & $55-65$ \\
\hline Hemi-cellulose & $10-15$ \\
\hline Pectin & $2-4$ \\
\hline Lignin & $10-20$ \\
\hline Water soluble materials & $1-4$ \\
\hline Fat and wax & $0.15-0.3$ \\
\hline Ash & $0.7-1.5$ \\
\hline \multicolumn{2}{|c|}{$\begin{array}{c}\text { Chemical composition ofJute Fiber (courtesy } \\
\text { by www.testextextile.com) }\end{array}$} \\
\hline Cellulose & $65 \%$ \\
\hline Hemi-cellulose & $22.5 \%$ \\
\hline Lignin & $11 \%$ \\
\hline Fat and Wax & $0.3 \%$ \\
\hline Water Soluble Materials & $1.2 \%$ \\
\hline
\end{tabular}



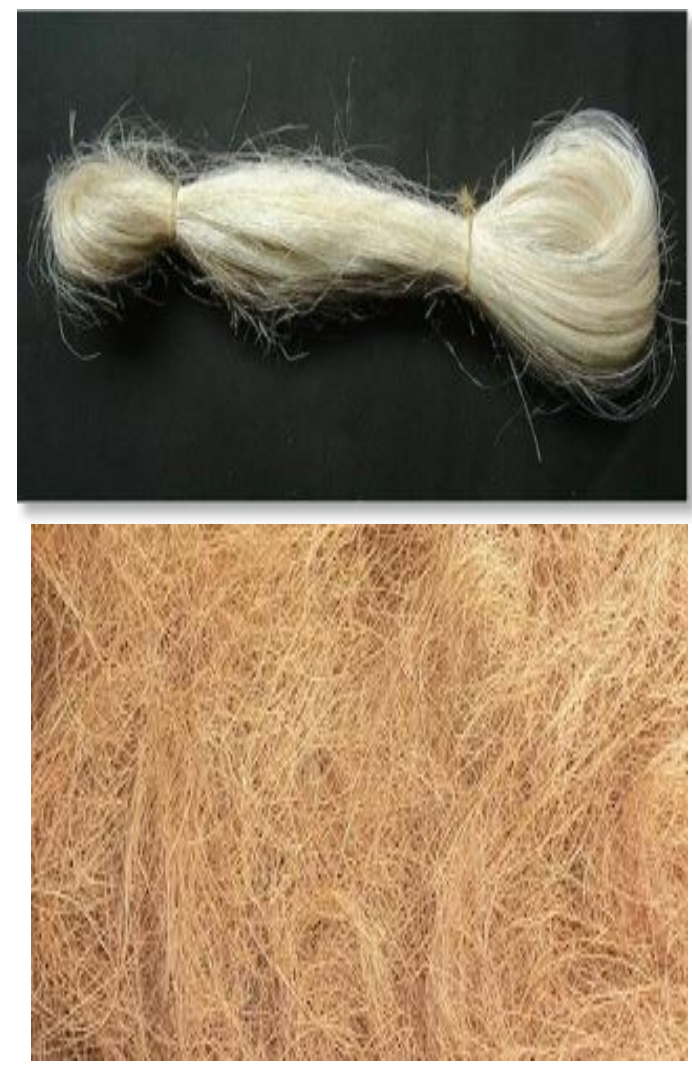

Fig 1 Sisal and jute

\section{TEST PROCEDURE}

various tests were done inside the exploration office for finding the record and assorted noteworthy spots of the soils used sooner or later of the test. Compaction checks, direct shear tests and CBR assessments have been finished with the advantage of the utilization of incredible rates of sisal and jute strands had been united with fly slag texture for discovering pervasive dimension of sisal and jute. The data of these tests are given inside the going with fragments

Rundown homes :in vogue techniques bolstered inside the individual I.S. Codes of movement [ IS:2720 (Part-5)- 1985; IS:2720 (Part-6)- 1972 ],were found at the comparable time as finding the Index houses viz. Liquid control, Plastic restriction and Shrinkage bind of the models tried this examinations.

Compaction houses: incredible moistness content material surface and most dry thickness of fly searing remains was picked as per I.S overpowering compaction research (IS: 2720 (portion 7)- 1980).

Direct Shear and California Bearing Ratio (CBR) checks: The quick shear and CBR checks were practiced in the examination focus similarly as with respect to IS Code (IS: 2720 (segment thirteen)- 1986) and i.S.Code (IS: 2720 (part sixteen)- 1979) independently as exhibited in Figs. 2\&three.

one in every one of the an insightful chances of sisal and jute sustaining materials used in flyash materials .the perfect dimension of sisal and jute texture with the supportive resource of dry unit weight of soil changed into blended reliably with the earth. The water content material just like OMC of untreated soil changed into added to the fly ash in little options and joined by methods for hand until uniform mixing of the sisal and jute become ensured. The models have been reviewed in a $6 \mathrm{~cm} \times 6 \mathrm{~cm}$ rectangular field at commonplace stresses of zero.five, 1, 1.five, $2,2.5 \mathrm{~N} / \mathrm{mm} 2$ for each dimension of sisal and jute material with fly blazing remains and sheared at an expense of one. $25 \mathrm{~mm} / \mathrm{min}$. The graph end up plotted among standard strain and shear oppose disillusionment for each dimension of sisal and jute for procuring the shear control parameters. The California Bearing Ratio (CBR) tests were conducted in the laboratory by using a standard California Bearing Ratio (CBR) testing machine.

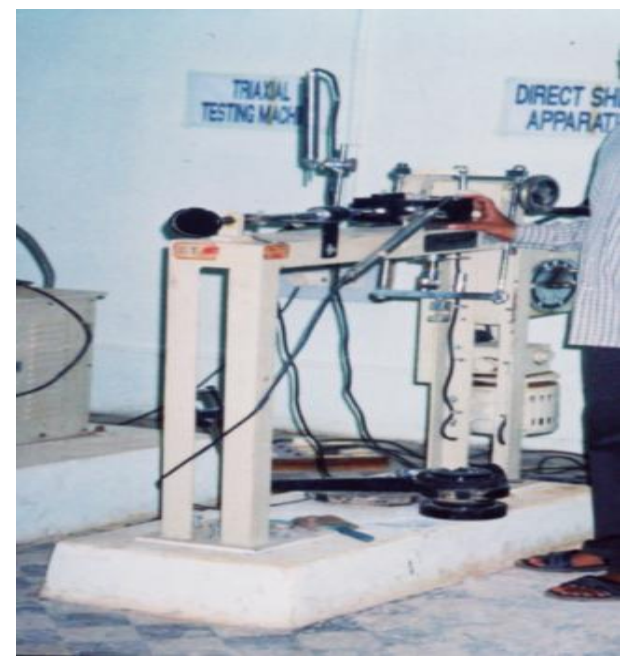

Fig.2 Direct Shear Test Apparatus

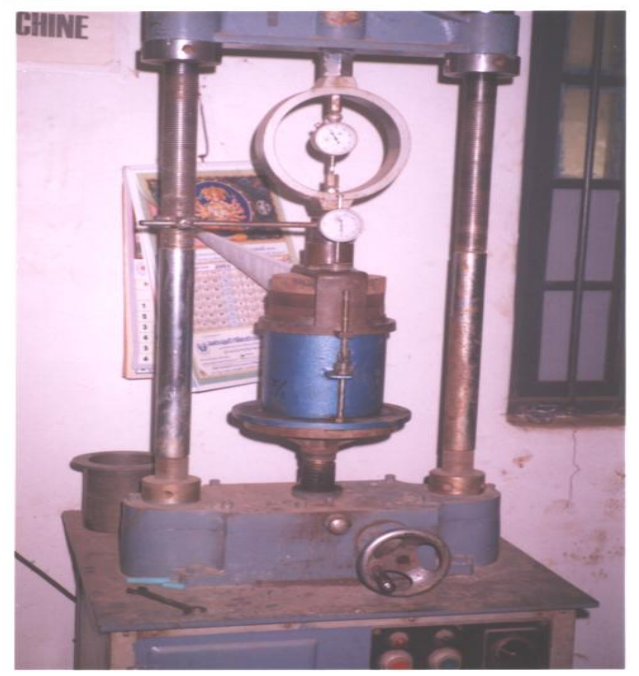

Fig.3 California Bearing Ratio Test Apparatus

\section{Preparation of Model Flexible Pavement}

The version flexible black-top is set up in a circuitous metal tank of $60 \mathrm{~cm}$ separation crosswise over with a significance of $30 \mathrm{cms}$, out of which $20 \mathrm{~cm}$ significance is for lying sub grade, $5 \mathrm{~cm}$ is sub base and $5 \mathrm{~cm}$ for base path. The widespread soil used as a sub degree that's accumulated at a significance of zero. $3 \mathrm{~m}$ beneath the floor degree. The every soil layer is compacted to two.Zero $\mathrm{cm}$ thickness in 10 layers to a complete thickness of $20 \mathrm{~cm}$ to its maximum advantageous clamminess substance and most first-rate dry thickness within the smooth metallic check tank. At the 
prepared soil sub grade, fly crimson hot flotsam and jetsam sub base material mixed with water at OMC is laid in layers all of two. $5 \mathrm{~cm}$ compacted to a whole scale thickness of five. 0 $\mathrm{cm}$. The sub base layer is compacted identifying with MDD and OMC. For the sisal and jute fortifying material, flyash is blended with great size of sisal and jute (gained from research recognition shear and CBR take a look at outcomes) and compacted inlayers to an entire of thickness five.Zero $\mathrm{cm}$. Those layers are also compacted to OMC and MDD and laid at the organized sub grade. On the organized sub base,layers of WBM-III all of two. $5 \mathrm{~cm}$ compacted thickness, turn out to be laid to a entire thickness of 5.Zero $\mathrm{cm}$ as confirmed up within the Fig. 4. A sand mattress of $2 \mathrm{~cm}$ thick is placed earlier than circumstance of sub evaluation soil inside the tank and sand channels have been given by strategies for 3 vertical sand sections of $4 \mathrm{~cm}$ width from base to pinnacle of the sub assessment soil for submersion.

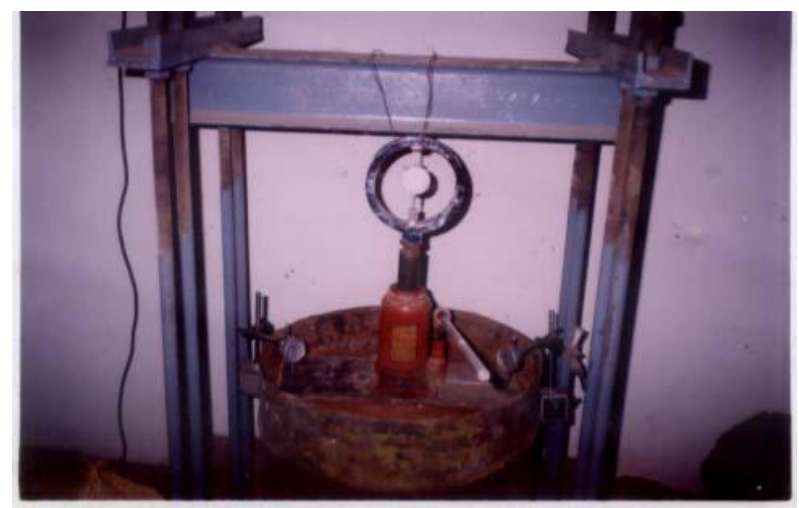

Fig. 4 Laboratory Cyclic Load Test Apparatus

\section{Cyclic Load Testing}

Cyclic Plate weight tests were performed on the exploration focus structure versatile black-top contraption in a round metal tank of estimation six hundred mm, best case scenario sogginess content material. The stacking is finished by methods for a round metallic plate of $10 \mathrm{~cm}$ separation crosswise over put on the inside at the model black-top. The metallic tank is arranged on the stage of the weight taking a gander at machine. A 5 ton limit exhibiting ring is acquainted with the stacking body and the development post welded to the round plate is passed on in contact with showing ring, dial proportions of least depend zero.01 $\mathrm{mm}$ are arranged at the metal living game plans welded to the vertical bar to degree the vertical evacuations of the stacking plate. the weight is performed in expansions like tire stress of 500, 560,630,seven hundred and a thousand $\mathrm{kPa}$. At each weight increment exceptional cycles of stacking and exhausting is developed till there's no titanic exchange deformation between dynamic cycles. The finding is in addition continued until the occasions of failure to document the remainder of the piles. the ones tests are executed at OMC and MDD for sisal and jute - fly powder stronghold and unreinforced fly red hot stays model tanks.

\section{TEST RESULTS}

I.S heavy compaction, direct shear tests and CBR tests were conducted as per (IS: 2720 (Part-7)-1980), IS: 2720 (part XIII, 1986), IS: 2720 (Part-16)-1979)respectively in the laboratory for fly ash materials with and without sisal and jutewith a view to find the optimum percentage of sisal and juteand the results are furnished below.

Compaction, Direct Shear and California Bearing Ratio (CBR) Test Results

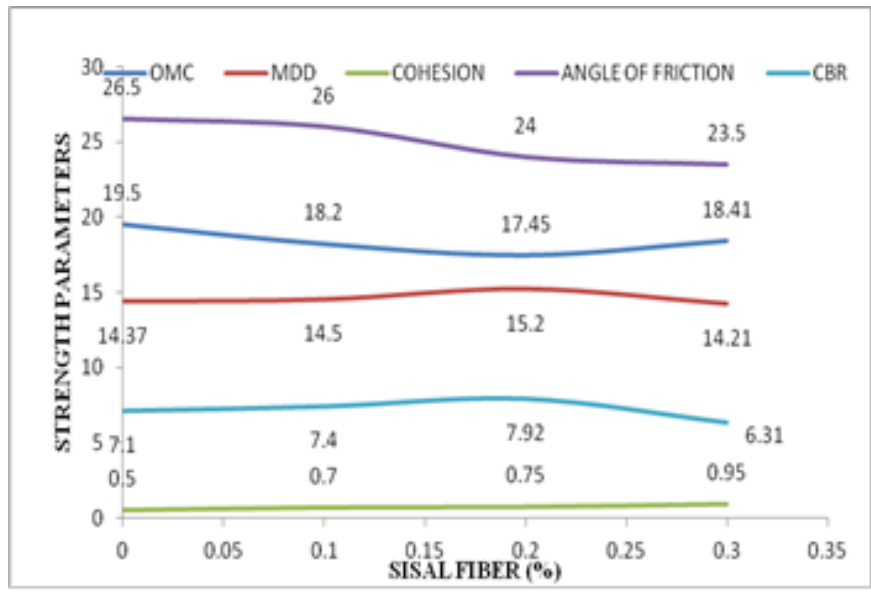

Fig.5(a) Strength Parameters for Fly ash Reinforced with Different Percentages of Sisal

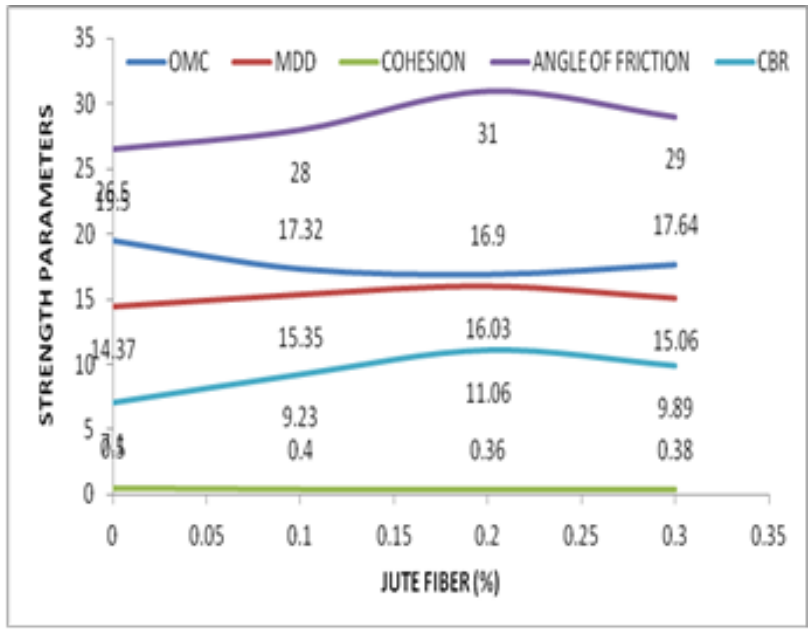

Fig.5(b) Strength Parameters for Fly ash Reinforced with Different Percentages of jute

In attitude on the above consequences, it is visible that, fly blazing garbage sustained with sisal and jute, the edge of internal touch regards are decreased from 26.50 to 240 up to zero. $2 \%$ of sisal and the threshold of indoors crushing regards are extended from 26.50 to 310 up to zero. $2 \%$ of jute and the relationship regards are prolonged from 0.5 to $0.95 \mathrm{kN} / \mathrm{m} 2$ of sisal fiber and lessened from zero. 5 to 0.38 $\mathrm{kN} / \mathrm{m} 2$ of jute with $0.2 \%$ and further extension of sisal and jute does no longer impact the motive of inner disintegration and affiliation, as confirmed up in Fig.5 (a\&b) .It's miles visible from the results, for fly slag bolstered with sisal and jute, soaked CBR regards are prolonged from 7.1 to 7.Ninetyof sisal fiber and 7.1 to 11.06 of jute fiber as much as $0.2 \%$ in addition improvement of sisal and jute does no longer impact the CBR regard. From the outcomes of direct shear and California Bearing Ratio checks, the proper costs 
of sisal and jute for fly powder substances is zero. $2 \%$.It is visible from the test outcomes that the fly searing stays fortified with waste sisal and jute has shown better execution whilst regarded in a unique way on the subject of unreinforced fly slag cloth.

Weight check outcomes on Fly crimson heat staysSubbase

The weight - deformation twists for exceptional version bendy pavements are created on fly purple warm remains subbase laid on massive soil subgrade, showed up in figs. $6 \& 7$. At all the misshapening tiers, sisal and jute invigorated fly searing remains subbase stretch has seemed better execution whilst diverged from unreinforced fly ash sub base stretch. At maximum proper specific, the complete and adaptable misshapenings of fly blazing flotsam and jetsam at a shop of $500 \mathrm{kPa}$ are proportional to three.Nine mm, 2.0 $\mathrm{mm}$; for untreated stretch and at a weight of $500 \mathrm{kpa}$ are identical to $3.39 \mathrm{~mm}, 1$.Fiftymm for fly slag with sisal and at a weight $500 \mathrm{kpa}$ are equal to a few.01 and $1.75 \mathrm{~mm}$ for fly ash with jute strengthened stretch separately.

It is probably visible that the pile passing on point of confinement is internal and out prolonged and adaptable twists are reduced for the sisal and jute - fly purple hot remains strengthened sub base stretch seemed differently in relation to unreinforced fly slag sub base stretch. Better mutilations are recorded at higher weight powers exactly as anticipated.

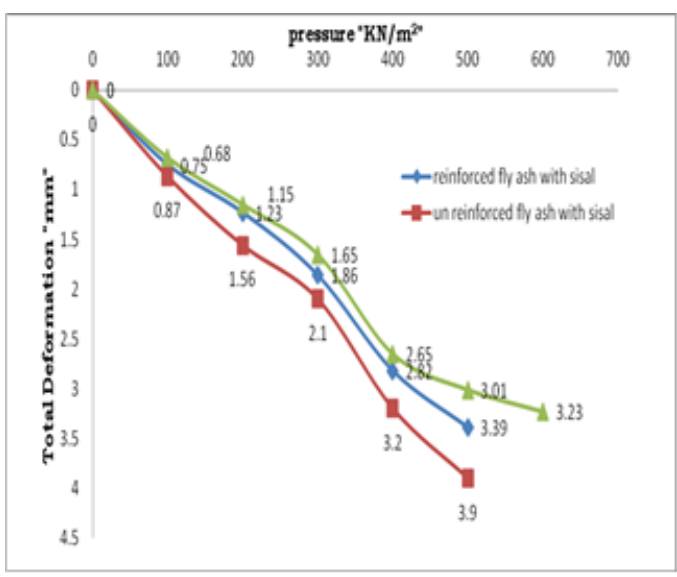

Fig. 6 Pressure-Total deformation Curves for Different Pavement Stretches laid on Expansive Soil subgrade

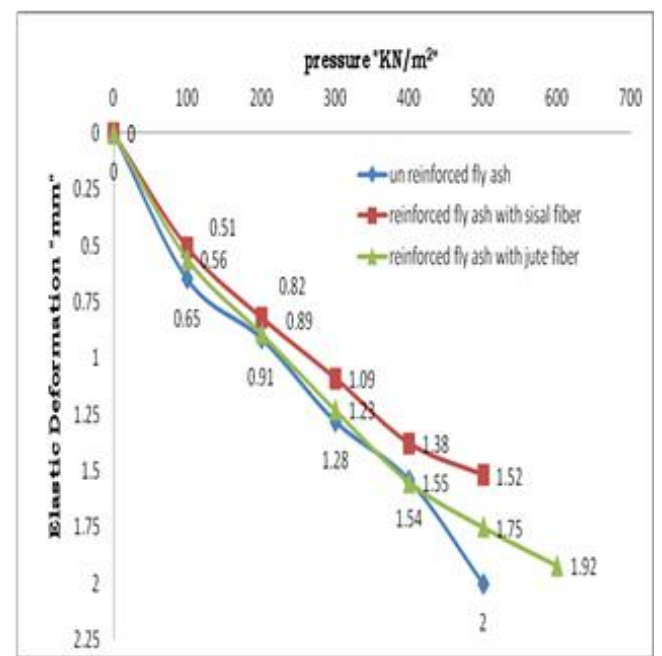

Fig. 7 Pressure-Elastic Deformation Curves for Different Pavement Stretches laid on Expansive Soil subgrade
The improvement in the store wearing limit may be credited to bleeding edge burden dispersing through fortified sub base quickly to the sub grade.

\section{CONCLUSIONS}

From the last result of direct shear and CBR tests, fly red hot stays sustained with special dimension of sisal and jute, the right dimension of sisal and jute fortress is same to zero. $2 \%$ of dry unit weight of soil. The development of sisal and jute material past zero. $2 \%$ does never again improve the power limit regards very. Extension of sisal and jute fuses in fly red hot garbage impacts in a noteworthy impact in the shear characteristics and CBR regards.

the entire and adaptable mutilation estimations of fly blazing remains bendy black-top gadget are progressed notwithstanding when stood out from fly powder by strategy for method for the game plan of the sisal and jute stronghold laid on broad soil sub level, on the other hand with the conventional bendy black-top machine.

With extension of fiber surface which fuses to fly slag, interestingly with fly red hot remains the adaptability is $20 \%$ creating

\section{REFERENCES}

[1] Hausmann, M.R. (1990). "Building musings of floor change," McGraw-Hill, Pub. Co. tremendous apple.

[2] Boominathan, A. In addition, Ratna Kumar, J. (1996). "Lime oversaw Flyash as Embankment texture", IGC-96, Madras, pp. 523-526.

[3] Veerendra Singh V., Kumar N. In addition, Mohan. D, (1996). "Use of Flyash in Soil Stabilization for Roads", IGC-ninety six, Madras, pp. 411-414.

[4] Murthy A.V.S.R. (1998). "Utilization of Flyash for Embankment creation", Use of flyash in Roads and Embankments, CRRI-New Delhi, pp. 15-20.

[5] Guru Vittal. U.okay., and Murty, A.V.S.R. (1998). "feature of Flyash in street headway circumstance", Use of Flyash in Roads and Embankments CRRI-New Delhi, pp. 24-32.

[6] Consoli N.C., Prietto P.D.M. In addition, Ulbrich L.A. (1998): impact of Fiber and Cement Addition on lead of Sandy Soil, journal of Geotechnical and Geoenvironmental Engineering, Vol-124, no.12, pp. 1211-1214

[7] Boominathan, A. Likewise, Hari, S. (1999). "Lead of Flyash underneath Static and Cyclic Loading," IGC-ninety nine, Calcutta, pp. 324-326.

[8] Kaniraj, S. R. In addition, Havanagi, V. G. (2001) "direct of bond modification fiber-invigorated fly slag soil blends. magazine of Geo-specific and Geoenvironmental Engineering, vol. 127 , no. 7 , pp. 574584

[9] Kaniraj, S. R. Moreover, Havanagi, V. G. (2001) "lead of bond alteration fiber-fortified fly soot soil combos. journal of Geo-particular and Geoenvironmental Engineering, vol. 127, no. 7 , pp. 574584

[10] Pazare, ok.S.,Chatterjee, P. (2002) "Lead of silty soil strengthened with subjectively appointed strands". across the country class on ROTRAN, IIT, Kharagpur, pp. 3.41-3.forty eight.

[11] Jain, P.ok., Jain, R. Moreover, Kumar, R. (2003) "Direct of clearing dim cotton soil blended with nylon fiber", Proc. Indian Geotechnical appear, Roorkee, Vol-1, pp. 389-392 
[12] Kumar B.R.P and Sharma R.S. (2004). "effect of Flyash on Engineering spots of Expansive Soils," magazine of Geotechnical and Geoenvironmental Engineering, volume one hundred thirty, burden 7, pp. 764-767.

[13] Singh, V. Moreover, Prasad, H.S. (2004) "Usage of sand layer as subbase substances in street delivering on alluvial soil", Proc. IGC on floor Engineering: rising techniques, Warangal, Vol 1, pp. 494-496.

[14] Lindh and Mattsson, Nina (2004) "Composite soil created utilizing flexible waste and bond settled soil", 5 th overall gathering of floor improvement methodology, Malaysia, pp.195-202.

[15] Praveen Kumar and pratap Singh (2007): invigorated fly red hot remains sub bases in nation avenues, paper No.531.

[16] VenkataKoteswaraRaoPasupuleti, Satish Kumar Kolluru, Blessingstone $\mathrm{T}(2012)$ " impact of Fiber on Fly-Ash Stabilized Sub Grade Layer Thickness" by and large magazine of Engineering and advancement (IJET) Vol four No 3 Jun-Jul 2012, pp a hundred and forty-147.

[17] Prasad D S V, M.Anjan Kumar and G. V. R. PrasadaRaju (2013), "effect of Waste materials in Pavement introduction ",court examples of Indian Geotechnical appear - 2013, December 22-24,IIT-Roorkee ,pp 1-7.

[18] Mercy Joseph Poweth, SollyGeorge,Jessy Paul (2013), "look at on Use of Plastic Waste in road creation" ,by and large magazine of present day contemplates in mechanical getting, Engineering and development Vol. 2, trouble three, March 2013 ,pp 633-638.

[19] BJ Sushma, DSV Prasad, M AnjanKumar, GVR PrasadaRaju(2014),"A research nature of reinforced Flyash with Randomly passed on Fibers", generally speaking mag of Engineering creative work, www.Ijerd.Com, volume 10, issue 11 (November 2014), PP.69-seventy six.

[20] Srinivas.A, PG pupil,Dr.DSV Prasad, M AnjanKumar, Dr.GVRPrasadaRaju, "control qualities of Gravel-Flyash strengthened with Waste Fibers "overall journal of Engineering and realized Sciences (IJEAS) ISSN: 2394-3661, volume-2, trouble 1, January 2015.

[21] JoyantaMaity, Saurav partner, DebankarSengupta "programming of characteristic Fiber with Sand and Moorum for Subbase appearance of Roads" overall mag of Engineering and impelled contemplates development (IJEART) ISSN: 2454-9290, sum three, burden five, may similarly 2017.

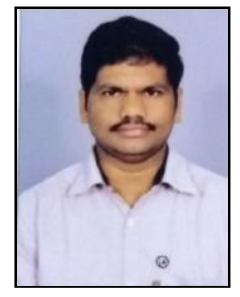

T.Venkateswararao working as Assistant Professor, VVIT,Nambur,Guntur District. He has 4 years experience in soil mechanics and foundation engineering area. He has completed M.tech at jntu Kakinada.

Mail:venkateswararaothumati@gmail.com,96038

28270

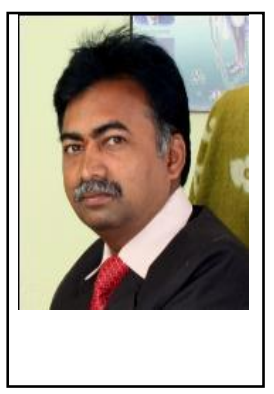

Dr. D. S. V. Prasad working as PrincipalBVC Engineering College, Odalarevu, AP, has more than 18 years of experience in teaching. Published more than 57 technical papers in National \& International Journals \& Conferences in the research area of soil mechanics and foundation engineering. He got a prestigious Crop's of Engineers Award constituted by IEI Journal. .

Mail: dsvp9@yahoomail.com,9392522444

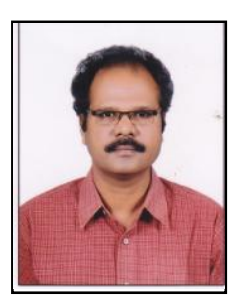

Dr.R.Ratna Prasad working as professor, VVIT,Nambur, Guntur District First. He has more than 20yrs experience in soil mechanics and foundation engineering. He has completed his Ph.D at jntu Kakinada.

Mail: rekapalli.rp@gmail.com,9490114986.

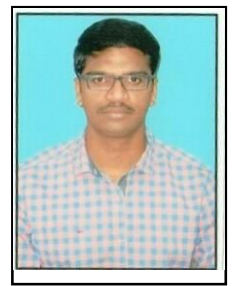

D.AudityaSairam working as Assistant Professor, VVIT,Nambur,Guntur District. He has 4 years experience in structural engineering area. He has completed M.tech at jits college of engineering.. Mail : dasairam102@gmail.com,9010410890 